\title{
Advances in Crosswell Electromagnetics: Steel Cased Boreholes
}

\author{
Barry Kirkendall \\ Phillip Harben \\ Pat Lewis
}

This paper was prepared for submittal to the

Society of Exploration Geophysicists (SEG)

1999 International Exposition and 69th Annual Meeting

Houston, TX

October 31-November 5, 1999

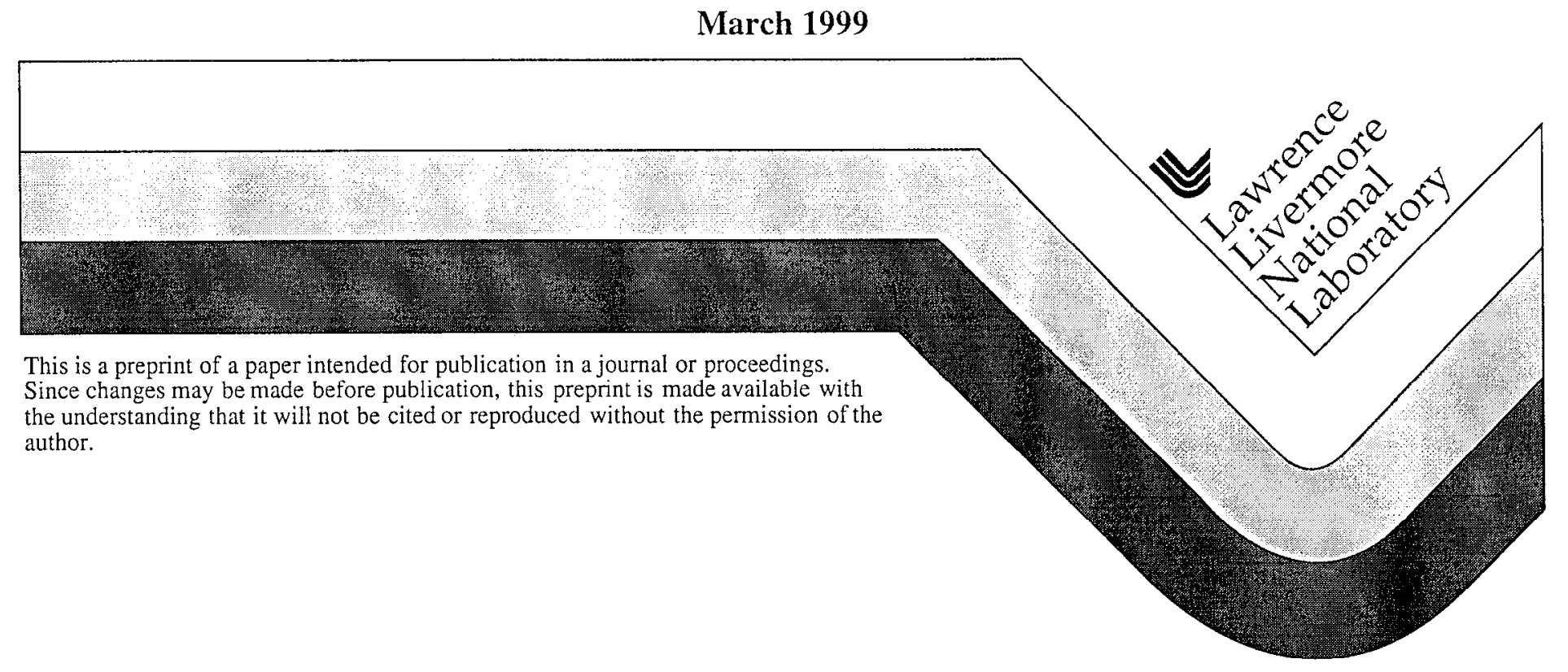




\section{DISCLAIMER}

This document was prepared as an account of work sponsored by an agency of the United States Government. Neither the United States Government nor the University of California nor any of their employees, makes any warranty, express or implied, or assumes any legal liability or responsibility for the accuracy, completeness, or usefulness of any information, apparatus, product, or process

disclosed, or represents that its use would not infringe privately owned rights. Reference herein to any specific commercial product, process, or service by trade name, trademark, manufacturer, or otherwise, does not necessarily constitute or imply its endorsement, recommendation, or favoring by the United States Government or the University of California. The views and opinions of authors expressed herein do not necessarily state or reflect those of the United States Government or the University of California, and shall not be used for advertising or product endorsement purposes. 


\section{Advances in crosswell electromagnetics: steel cased boreholes \\ Barry Kirkendall, Phillip Harben, Pat Lewis, Lawrence Livermore National Laboratory}

\section{Summary}

The Crosswell electromagnetic (EM) induction technique ideally measures the resistivity distribution between boreholes which may often be cased with carbon steel. Quantification of the effect of such steel casing on the induced field is the most significant limitation of the technique. Recent data acquired at a site in Richmond, California quantify the effect of steel casing on induction measurements and demonstrate this effect to be separable. This unique site contains adjacent steel and plastic wells in which frequency soundings demonstrate low spectrum $(1.0-50 \mathrm{~Hz})$ measurements an effective means of isolating the casing response frum the formation response. It is also shown that the steel casing effect on the induction coil is highly localized, and limited to less than 0.30 meters above and below the coil.

\section{Introduction}

Crosswell EM induction surveys have successfully characterized oil-field reservoirs, tracked steam floods, and monitored saltwater floods since the early 1990's. Currently, the most significant limitation of crosswell EM concerns the difficulty of data acquisition through wells cased in carbon steel - the most common steel used in the oil patch.

Wu and Habashy (1994) established a foundation for this study with experimental and modeling results regarding ' the effect of laboratory steel casing on the electromagnetic signals transmitted through such casing. Although the conductivity, magnetic permeability, and the casing wall thickness all affect the induced EM field, it was found that casing thickness and conductivity of carbon steel do not vary significantly. It is therefore the magnetic permeability which most affects the EM field. Wilt et al. (1995) suggest that the casing effect is localized within the pipe section that includes the sensor and that the effect of the casing can be separated.

In this study, using data acquired from the Richmond Field Station (RFS) site in Richmond, California (figure 1) which contains both plastic and carbon steel wells, the phase and amplitude effects of a carbon steel well on crosswell EM measurements are directly measured and shown to be linearly separable. This study also quantifies the localized casing effect discussed in Wilt et al. (1995)

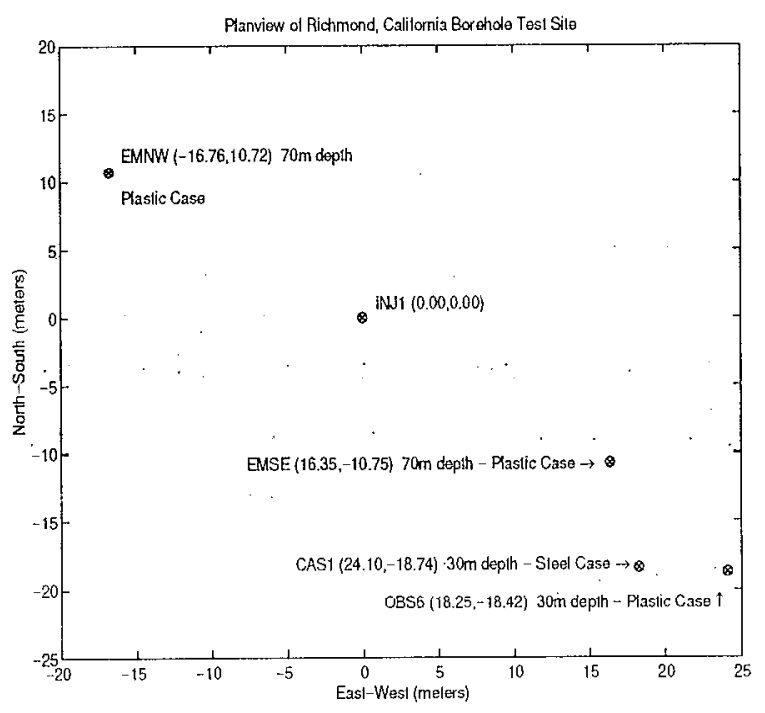

Figure 1: Planview of the Richmond Field Statiun well site. The close proximity of the steel (CAS1) and plastic wells (OBS6) allows the assumption of equivalent stratigraphy between these two receiving wells.

\section{Field Description}

Detailed information on the field system employed and a review of the crosswell technique and theory can be found in Kirkendall el al. (1999). The Richmond Field Station (RFS), located on land managed by the University of California, provided an ideal site for examining the steel casing effect on EM induction fields. The field site and test holes are shown in figure 1. This experiment utilized wells EMNW, a 70 meter deep plastic hole, OBS6, a 30 meter deep plastic hole, and CAS1, a $30 \mathrm{~m}$ deep steel cased hole. This experiment used well EMNW as the trarismit location and wells OBS6 and CAS1 as the receive location. This geometry provided a 


\section{Advances in crosswell EM}

steel cased well within 8 meters of a plastic cased well for receive locations, and a plastic cased well at five times the distance for transmit locations; a unique opportunity for examining induction through steel cased wells.

The geological section of the RFS site can be divided into two primary units: a $40 \mathrm{~m}$ layer of unconsolidated deltaic deposits and a basement of sandstone or shale. The unconsolidated deposits are primarily bay mud and clay with occasional layers of sand and gravel. One strata, 30 m depth, was the target zone for a 1993 salt water injection experiment. Mostly purnped out in 1995, the residual leaves a small but significant resistivity signature. The resistivity of the clay ranges from 5 to $20 \mathrm{ohm}-\mathrm{m}$, while the sand and gravel ranges from 12 to $33 \mathrm{ohm}-\mathrm{m}$ (Tseng et al., 1997).

\section{Discussion of Results - Conclusions}

With the transmit coil in EMNW at 14 meter depth, the receive coil is placed at depths of 8,14 , and 22 meters in wells CAS1 (steel) and OBS6 (plastic). At each depth, the frequency is swept from $0.707 \mathrm{~Hz}$ to $500 \mathrm{~Hz} .500 \mathrm{~Hz}$ is the frequency ceiling due to increasing attenuation with increasing frequency in induction through steel casing; above this frequency, signal to noise ratio (SNR) is

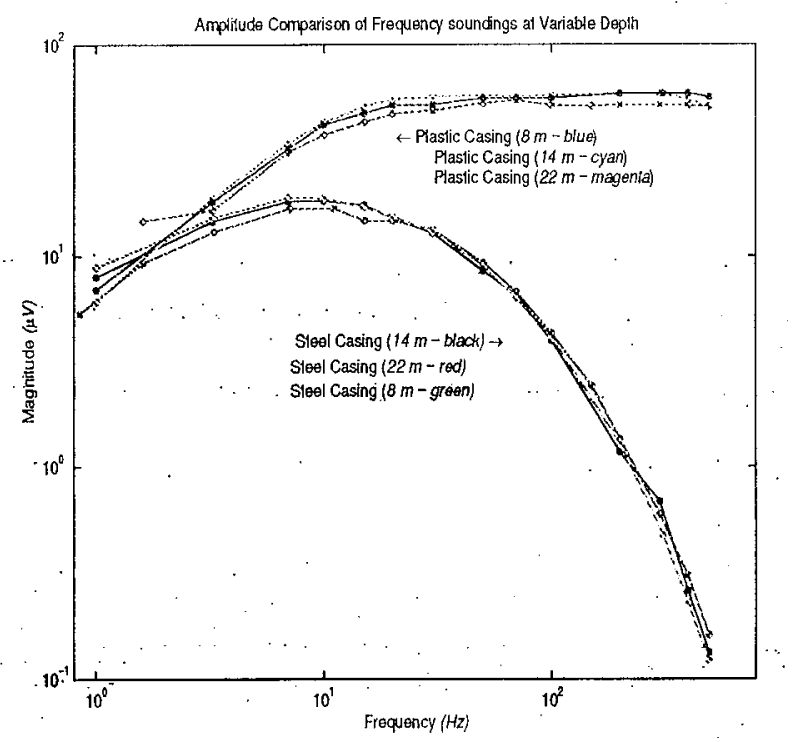

Figure 2: Receiver magnitude response to transmitter frequency sounding. Variable receiver depth of 8; 14, and 22 meters. Each depth is the center of one continuous pipe section. extremely low. The magnitude (figure 2) and phase (figure 3) of this frequency comparison demonstrate that the steel casing effect is equivalent to the plastic casing effect at frequencies below $4 \mathrm{~Hz}$. Essentially, this is interpreted as a response, below $4 \mathrm{~Hz}$, which is independent of steel casing and formation effects. Frequencies above the DC .limit increasingly show the effect of the ferromagnetic steel casing, and simultaneously, the formation response.

Nuances of EM induction physics force typical operating frequencies for well-resolved crosswell EM investigations above $100 \mathrm{~Hz}$, thus, significant effects from the steel casing will appear. Concerning this problem of steel cased wells, a difference calculation between the steel and plastic casing response at a selected operating frequency taken from figures 2 and 3 , would subtract the effect of the steel casing from the data; that which remains is the formation response. Although this is a strong processing step, noisy environments and site-specific issues may dictate further conditioning.

Aside from frequency, in the induction regime, casing conductivity, casing thickness, and magnetic permeability are the only significant variants concerning a section of steel casing, and of these three, the relative magnetic permeability $(\mu)$ has the most significant effect between

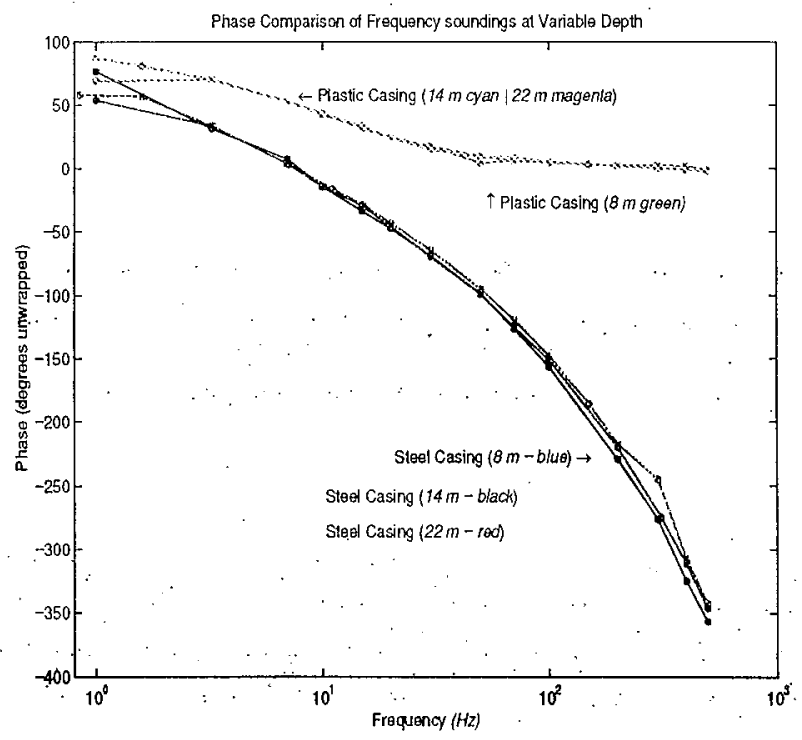

Figure 3: Receiver phase response to transmitter frequency sounding. Conditions are equal to figure 2. 


\section{Advances in crosswell EM}

pipe sections due to varying ferromagnetic levels in steel and physical impacts (Wu and Habashy, 1994). Figures 2 and 3 begin to demonstrate this behavior at frequencies above $50 \mathrm{~Hz}$, with increasing, although slight, differences in magnitude and phase.

Figures 4 and 5 are acquired from a stationary transmit coil at $14 \mathrm{~m}$ depth and a receive coil ranging from $4-24$ meters depth. Figure 4 plots the magnitude versus depth for two frequencies $(30 \mathrm{~Hz}$ and $150 \mathrm{~Hz}$ ) in both steel and plastic holes, while figure 5 plots the phase versus depth. In both figure 4 and figure 5 , the plastic casing effect does not change as a function of frequency which is predicted. The steel casing affects both the magnitude (increasing energy loss with increasing frequency) and phase (increasing phase lag with increasing frequency), again in a predictable manner. The increasing oscillations at shallow depths with increasing frequency. in figures 4 and 5 is consistent with passive background noise measurements at the RFS site; more noise is present as frequencies increase from $30 \mathrm{~Hz}$ to 150 $\mathrm{Hz}$.

It is important to state that the steel casing extends to only 23 meters depth; bay mud terminates the well at 24 m. In figure 5, the phase of the steel casing jumps rapidly to the plastic casing limit within the span of 1 meter.

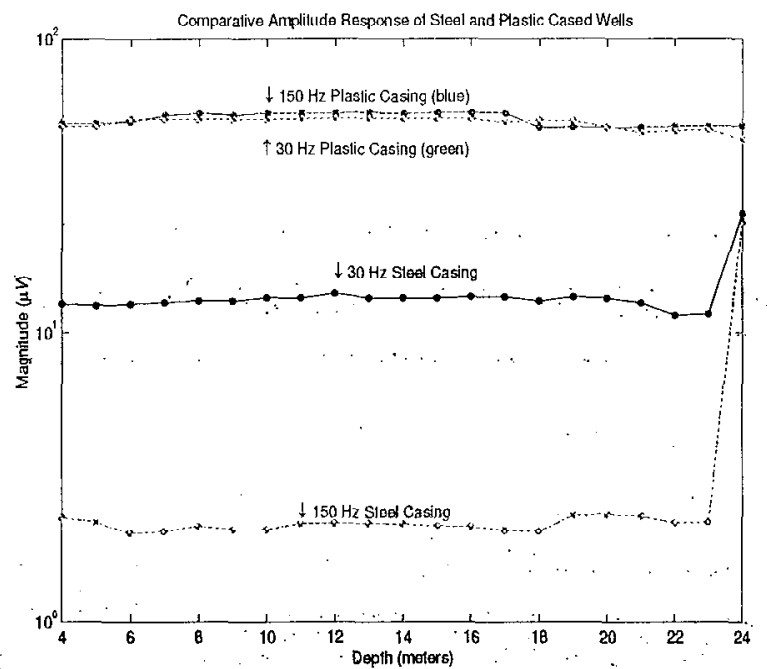

Figure 4: Crosswell magnitude profiles taken at two different frequencies $(30$ and $150 \mathrm{IIz}$ ). Note the abrupt steel cased phase jump at 23 meters depth.
Knowledge of the instrument geometry and hole depth determines the precise receiver location where this phase jump begins - the steel casing which is within $18 \mathrm{~cm}$ of the edge of the induction coil is the only pipe section which affects the phase measurement, and this behavior is independent of frequency.

The magnitude of the induction coil is affected by slightly more casing - only the steel casing within .30 meters of the induction coil edge affects the magnitude measurement. The response, therefore, of the induction coil to steel casing is highly localized. This localization can facilitate processing in transitional areas, such as pipe connections, steel collars, and permanent seismometers.

\section{Acknowledgements}

The authors would like to thank EMI Inc. and Michael Wilt for the use of testing equipment, helpful advice, and equipment assistance.

This work was performed under the auspices of the U.S. Department of Energy by Lawrence Livermore National Laboratory under Contract W-7405-Eng-48.

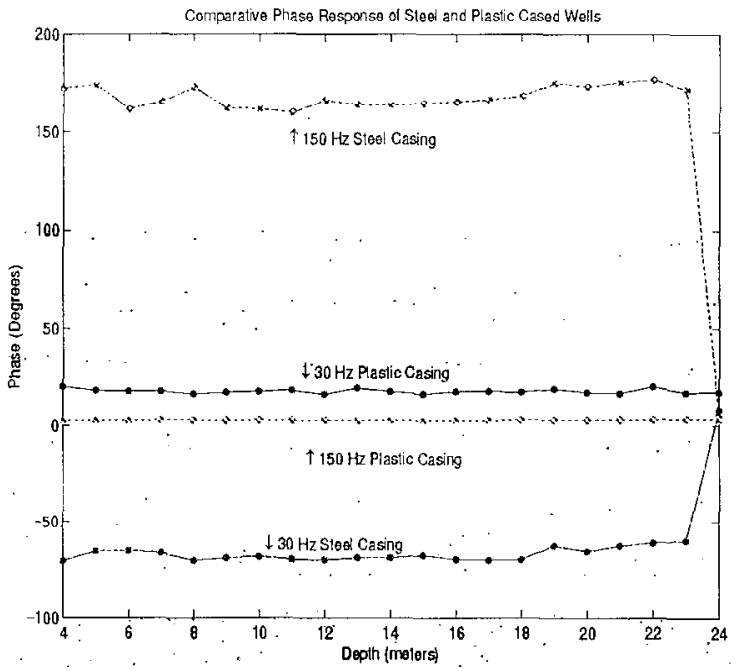

Figure 5: Crosswell magnitude profiles taken at two different frequencies $(30$ and $150 \mathrm{~Hz}$ ). The oscillation with increasing frequency at shallow depths in steel casing is a result of the site-specific background noise. 


\section{References}

Kirkendall, B.A., Lewis, J.P, Hunter, S., and Harben, P.E., 1999, Progress in Crosswell Induction Imaging for EOR: Field System Design and Field Testing, Lawrence Livermore National Laboratory, UCRL-ID 133468, 17 p.

Tseng, H.-W., Becker, A., Wilt, M., and Deszcz-Pan, M., 1997, Fluid injection monitoring with a borehole-to-surface electromagnetic method: Lawrence Berkeley National Laboratory Report LBNL-40130.

Wilt M.J., Alumbaugh, D.L., Morrison, H.F., Becker, A., Lee, K.H., and Dezcz-Pan, M., 1995, Crosswell Electromagnetic Tomography: System Design Considerations and Field Results, Geophysics, 60,3, p. $871-885$

Wu, X., and Habashy, T., 1994, Influence of Steel Casings on Electromuynetic Signal, Geophysics, 59, 3, p. $378-391$ 